\title{
Glembatumumab Vedotin
}

\author{
National Cancer Institute
}

\section{Source}

National Cancer Institute. Glembatumumab Vedotin. NCI Thesaurus. Code C78449.

An antibody-drug conjug ate, consisting of the fully human monoclonal antibody CR011 directed against glycoprotein NMB (GPNMB) and conjug ated via a cathepsin B-sensitive valine-citrulline (vc) linkage to the cytotoxic agent monomethyl auristatin E (MMAE), with potential antineoplastic activity. Upon administration, the monoclonal antibody CR011 moiety binds to glycoprotein nmb (GPNMB), expressed on the surfaces of a variety of cancer cell types; upon endocytosis, the synthetic dolastin analogue MMAE is released via enzymatic cleavage into the tumor cell cytosol, where it binds to tubulin and inhibits tubulin polymerization, which may result in G2/M phase arrest and apoptosis. The vc linkage system is highly stable in serum, rendering the cytotoxicity of glembatumumab vedotin specific for GPNMB-positive cells. GPNMB is a transmembrane protein overexpressed on the surfaces of various cancer cell types, including melanoma, breast, and prostate cancer cells. 